\title{
Solange Muglia Wechsler: Trajetória Profissional ${ }^{1}$
}

\author{
Tatiana de Cassia Nakano ${ }^{1}$ \\ ${ }^{1}$ Pontifícia Universidade Católica de Campinas, SP, Brasil.
}

Resumo: O presente texto tem, como objetivo, prestar uma homenagem à pesquisadora Solange Muglia Wechsler, pela sua relevância e atuação na área da Psicologia. A partir da retomada da sua história pessoal e trajetória acadêmica e profissional, o artigo busca apresentar suas principais contribuições para a Psicologia, mais especificamente para a área da avaliação psicológica e construção de testes psicológicos, notadamente nas temáticas da criatividade, inteligência, talentos, estilos cognitivos, altas habilidades/superdotação, temperamento e Psicologia positiva.

Palavras-chave: Biografia, Trajetória Profissional, História de Vida.

\section{Solange Muglia Wechsler: Professional Trajectory}

Abstract: The present text aimed to honor researcher Solange Muglia Wechsler, for her relevance and performance in the area of Psychology. The article seeks to present her main contributions to psychology, specifically to the psychological assessment and psychological tests construction, especially in the subject of creativity, intelligence, talents, cognitive styles, giftedness, temperament and positive psychology.

Keywords: Biography, Professional Trajectory, Life History.

\section{Solange Muglia Wechsler: Trajectoria Profesional}

Resumen: El presente texto tiene como objetivo, rendir un homenaje a la investigadora Solange Muglia Wechsler, por su relevancia y actuación en el área de la Psicología. A partir de la retomada de su historia personal y trayectoria académica y profesional, el artículo busca presentar sus principales contribuciones a la psicología, más específicamente para el área de la evaluación psicológica y construcción de pruebas psicológicas, especialmente en las temáticas de la creatividad, inteligencia, talentos, estilos cognitivos, altas habilidades/superdotación, temperamento y psicología positiva.

Palabras clave: Biografia, Trayectoria Professional, Historia de Vida.

\footnotetext{
${ }^{1}$ A autora agradece a colaboração de Larissa Muglia Wechsler, Amanda Muglia Wechsler, Leandro da Silva Almeida, Eunice Maria Lima Soriano de Alencar, Raquel de Souza Lobo Guzzo e Claudio Simon Hutz, os quais, gentilmente, enviaram seus depoimentos, autorizando seu uso nessa homenagem.
} 


\section{História pessoal}

Solange nasceu em Muriaé, MG. Filha de Luis Muglia e Margarida Barreto Muglia, ela é a mais nova das três filhas do casal (Angela, Regina e Solange). Morou na sua cidade de nascimento até os 15 anos, época em que se mudou para o Rio de Janeiro para cursar o Ensino Médio.

Lá permaneceu por nove anos, até completar a faculdade de Psicologia, curso que escolheu devido ao seu interesse em entender como as pessoas pensam. Segundo suas filhas, Solange sempre disse ser fascinada com o pensamento infantil, principalmente. Buscou tal curso perante sua curiosidade em saber mais sobre crianças. Em 1974 se casou com Francisco e, no mesmo ano, mudou-se para Taubaté. Ficou nessa cidade por dois anos, quando se mudou para Athens nos Estados Unidos, onde cursou seu mestrado e doutorado (1976-1981).

Em 1981 voltou para o Brasil, mais especificamente, para o Rio de Janeiro, sendo que, dois anos depois, nasceu sua primeira filha, Amanda. Muda-se para Brasília e lá, no ano seguinte, nasceu Larissa. Permanece na capital brasileira até 1990, quando se muda para Campinas, SP, cidade em que permanece até hoje.

Quando não está se dedicando à Psicologia, Solange adora pintar. Faz aulas de pintura há anos e, inclusive, já pintou diversos quadros que enfeitam sua casa e de suas filhas. Também gosta de frequentar academia e fazer atividades com seus cachorros. Ela tem dois huskies siberianos (Iuri e Boris), um golden retriever (Brian) e um vira-lata (Achado). Passear com eles e fazer as atividades da escola dos cachorros com o marido estão entre seus hobbies.

\section{Formação e atuação profissional}

Formou-se em Psicologia pela Pontifícia Universidade Católica do Rio de Janeiro em 1974. Imediatamente ingressa como professora substituta da Faculdade de Filosofia, Ciências e Letras de Lorena, onde permanece pelo período de um ano (1974-1975). No ano seguinte (1976) ingressou no mestrado em Psicologia Escolar na University of Georgia, onde obteve o título em 1978 com a dissertação “Teacher's training creativity program", sob orientação de Catherine Bruch.

Ao final do mestrado, Solange ingressa no doutorado em Psicologia Educacional na University of Georgia, orientada por Paul Torrance. Sua tese, intitulada "Identifying verbal creative strengths in the Torrance Test of Creative Thinking” foi defendida em 1981.
Nesse mesmo ano, Solange ingressa, como professora adjunta, da Universidade Gama Filho, como diretora do serviço de Psicologia Escolar e pesquisadora do programa de pós-graduação em Psicologia e como professora titular da Pontifícia Universidade Católica do Rio de Janeiro, onde desempenhou atividades de pesquisa no curso de pós-graduação.

No ano seguinte (1982) passa a atuar como professora titular da Universidade de Brasília, onde permaneceu até 1990. Na instituição, dentro da linha de pesquisa Psicologia do Ensino e Aprendizagem, ministra aulas no curso de pós-graduação e graduação, orientando estágios e atividades de extensão. Durante dois anos assume a direção da Clínica Aplicada de Psicologia. Em 1986 ingressa em um pós-doutorado na University of Georgia, no Torrance Center of Creative Studies.

Um segundo pós-doutorado é iniciado em 1990 na University of Buffalo, vinculada ao Creative Education Foundation. Em 1991 ingressa na Pontifícia Universidade Católica de Campinas, onde permanece até hoje. Nesta instituição, atuando como professora titular, Solange desenvolve atividades na linha de pesquisa intitulada Instrumentos e Processos em Avaliação Psicológica, coordenando o Laboratório de Avaliação e Medidas Psicológicas (LAMP).

Atuou ainda como professora convidada para ministrar cursos em diferentes universidades internacionais: Espanha: Universidad de Sevilha, Universidad Autonoma de Madrid, Universidad Complutense de Madrid e Universidad Santiago de Compostela; Portugal: Universidad Lusíadas e Universidad do Minho; Argentina: Universidade Federal de Buenos Aires e Universidad de Palermo, Uruguai: Universidad Catolica del Uruguay.

\section{Atuação como pesquisadora}

Solange é pesquisadora nível $1 \mathrm{~B}$ do Conselho Nacional de Desenvolvimento Científico e Tecnológico (CNPq). Tem atuado como membro de corpo editorial de onze revistas científicas, nacionais (E-Psi- Revista Eletrônica de Psicologia, Educação e Saúde; Estudos de Psicologia Campinas; Avaliação Psicológica) e internacionais Journal of Happiness and Well-Being; School Psychology Quartely; International Journal of Creativity and Problem Solving; European Journal of Education and Psychology; Psychology in the Schools; Revista Iberoamericana de Diagnóstico e Evaluación Psicológica; Psicodebate). Também contribui como revisora de um 
grande número de periódicos, bem como juntamente às principais agências de fomento à pesquisa (Fundação de Amparo à Pesquisa do Estado de São Paulo e Conselho Nacional de Desenvolvimento Científico e Tecnológico). Compôs, enquanto assessora e consultora, comissões organizadoras, diretoras e científicas de eventos, nacionais e internacionais.

Ao longo de sua carreira, Solange publicou, por ocasião da consulta ao seu currículo lattes em maio de 2018, 124 artigos em periódicos científicos nacionais e internacionais, 18 livros, 44 capítulos de livros e mais de uma centena de trabalhos apresentados em eventos científicos nacionais e internacionais. Dentre suas produções mais relevantes, destacam-se os manuais de cinco testes psicológicos: Desenho da Figura Humana (Wechsler, 1996), Escala de Estilos de Pensar e Criar (Wechsler, 2006), Pensando Criativamente com Palavras - Testes de Torrance (Wechsler, 2004a), Pensando Criativamente com Figuras - Testes de Torrance (Wechsler, 2004b) e Teste de Criatividade Figural Infantil (Nakano, Wechsler, \& Primi, 2011).

Também tem atuado, de forma bastante intensa, na formação de recursos humanos. Solange já formou
48 mestres, 38 doutores, dois pós-doutorados e 42 alunos em iniciação científica. Atualmente encontra-se orientando dois mestrados, seis doutorados, um pós-doutorado e dois alunos de iniciação científica.

Atuou como membro fundadora de importantes associações científicas (Associação Brasileira de Criatividade e Inovação, Sociedad Peruana de Evaluación Psicológica, International Testing Comission, Associação Brasileira de Psicologia Escolar e Educacional, Associação Brasileira de Psicologia Positiva e Instituto Brasileiro de Avaliação Psicológica). Foi fundadora e primeira presidente da Associação Brasileira de Psicologia Escolar e Educacional (1994), tendo sido, por tal motivo, entrevistada sobre a área (Witter, 1996). Também foi Presidente do Instituto Brasileiro de Avaliação Psicológica (2001), Presidente da Associação Brasileira de Criatividade e Inovação (2007), sendo, atualmente, a presidente dessa associação.

Ao longo de sua trajetória profissional, Solange desenvolveu 18 projetos de pesquisa, sob sua coordenação, envolvendo diversos temas, construtos investigados e populações. Os títulos desses projetos são apresentados na Tabela 1 e ilustram bem essa diversidade de atuação ao longo de sua carreira.

Tabela 1

Projetos de pesquisa desenvolvidos e período.

\begin{tabular}{lc}
\hline Período & Título do projeto de pesquisa \\
\hline $1996-2005$ & Avaliação Cognitiva de crianças e jovens \\
$1997-2004$ & Avaliação das condições de ensino e programas educacionais \\
$1998-2009$ & Medidas e procedimentos para avaliação e desenvolvimento da criatividade \\
$2003-2008$ & Adaptação/ construção de Bateria de Habilidades Cognitivas de Woodcock-Johnson III - versão \\
infanto-juvenil
\end{tabular}


Como podem ser visualizados, seus temas de pesquisa se focam principalmente na construção de testes psicológicos, nas seguintes temáticas: criatividade, inteligência, talentos, estilos cognitivos, altas habilidades/ superdotação, temperamento e Psicologia positiva.

\section{Prêmios e títulos}

Ao longo de sua trajetória profissional, Solange recebeu, até o momento, diversos títulos e prêmios, como reconhecimento pela sua atuação na área (Tabela 2).

A importância dos prêmios, nacionais e internacionais, confirma a trajetória profissional de sucesso dessa importante pesquisadora. Não só profissionalmente, mas também como amiga e mãe, Solange tem sido descrita, pelos seus pares e familiares, como uma pessoa sempre cheia de energia e iniciativa, como poderá ser visualizado nos depoimentos a seguir.

\section{Alguns depoimentos sobre Solange}

Duas ideias importantes me surgem quando vinculo SolangeWechsler à Avaliação Psicológica. A primeira é que para se pesquisar qualquer constructo psicológico importa reunir primeiro instrumentos adequados de avaliação, fundamentados nalgum modelo teórico e assegurando, aos seus resultados, propriedades de precisão e validade. A segunda ideia é que não podemos estar ou andar de costas voltadas uns para os outros. Temos que integrar as associações internacionais e interagir com os especialistas na área para provocarmos avanços na avaliação psicológica (investigação, ensino e prática) nos nossos países (Leandro S. Almeida).
SolangeWechsler é uma pesquisadora que tem produzido contribuições altamente relevantes para a Psicologia Brasileira, especialmente na área da Avaliação Psicológica e nos estudos sobre Criatividade. Produziu instrumentos de avaliação muito úteis tanto para a pesquisa como para a prática profissional. Além das importantes contribuições científicas, Solange também sido uma profissional que contribui muito para o desenvolvimento da área, dirigindo associações científicas e organizando eventos. Muito me honra e orgulha ter uma colega e amiga tão qualificada (Cláudio Simon Hutz).

Tenho ainda muitas lembranças do período em que a Solange foi professora no Departamento de Psicologia da Universidade de Brasília. Chamavam-me a atenção a sua liderança, alta qualidade de produção científica, leveza e coragem de assumir riscos, como, por exemplo, iniciar uma nova associação e organizar um congresso, mesmo com recursos escassos. Essas são características que continuei a admirar ao longo dos anos, desde então. Solange é uma das pesquisadoras brasileiras que mais tem contribuído para o avanço do conhecimento referente a distintos tópicos da Psicologia Escolar e construção de instrumentos psicométricos. Como pessoa, irradia inúmeras qualidades admiráveis. É um modelo de pesquisadora e ser humano, que merece todo o nosso aplauso (Eunice Maria Lima Soriano de Alencar).

Depois de escrever essa homenagem, não poderia deixar de dar o meu depoimento. Solange contribuiu, de forma direta, para a minha trajetória pro-

Tabela 2

Prêmios e títulos recebidos.

\begin{tabular}{|cc|}
\hline Ano & Prêmio \\
\hline 1988 & Creative Scholar (Torrance Center of Creative Studies) \\
1990 & Personalidad destacada em las artes y ciências (Colégio de Psicólogos Carabobo, Venezuela) \\
2000 & Honra ao mérito em Psicologia Escolar (Associação Brasileira de Psicologia Escolar e Educacional) \\
2004 & Recognition in International Psychology (American Psychological Association) \\
2009 & Menção de Honra em Avaliação Psicológica (Instituto Brasileiro de Avaliação Psicológica) \\
2010 & Board Member International Testing Comission (International Testing Comission) \\
2012 & Service Award Editorial Board (Journal of School Psychology Quaterly) \\
2014 & Reconhecimento da Associação Brasileira de Psicologia Positiva (Associação Brasileira de Psicologia Positiva) \\
2015 & Professora honorária da Universidade Peruana Federico Villarreal (Peru) \\
\hline
\end{tabular}


fissional. Lá no segundo ano de graduação me deu a oportunidade de ingressar em seu grupo de pesquisa como bolsista de iniciação científica. Com tal ato, me abriu portas para uma área de atuação que eu ainda não conhecia e pela qual me apaixonei. Durante quatro anos frequentei seu grupo de pesquisa, do qual, aliás, nunca mais me desvinculei. Ela se tornou minha orientadora de mestrado e de doutorado e, após minha formação, tive a honra de retornar à instituição como sua colega de trabalho. Se hoje sou professora e pesquisadora, é por causa dela e do amor com que faz seu trabalho (Tatiana de Cassia Nakano).

Ao final dos anos 1980 eu terminei meu doutorado na USP sobre a Psicologia na Escola. Durante a revisão de literatura, encontrei no Dissertation Abstract um trabalho assinado por Dra. Wechsler e Dr. Oakland sobre a Psicologia Escolar no Brasil. Fiquei muito curiosa e, precisei entrar em contato com ela na UnB, porque não conseguia acessar o artigo. Depois desse contato combinamos de nos conhecer em uma mesa redonda no Congresso da Sociedade Brasileira de Psicologia em Ribeirão Preto, onde apresentamos nossas pesquisas sobre o tema da Psicologia na Escola. Desde essa época, estabelecemos entre nós uma amizade e parceria ao assumimos juntas o compromisso de fortalecermos a área no Brasil. Participamos de eventos da International School Psychology Association durante alguns anos, fundamos a Associação Brasileira de Psicologia Escolar e montamos a área de concentração de Psicologia Escolar no Programa de Pós-Graduação em Psicologia da PUC-Campinas. Solange era professora da UnB e não hesitou em pedir exoneração de seu cargo na Universidade de Brasília para vir morar em Campinas com a família e investir esforços para dar visibilidade à área. Foram anos de trocas e, com isso organizamos o primeiro congresso brasileiro de Psicologia Escolar e trouxemos, pela primeira vez, o Congresso Internacional para um país da América Latina. Solange é uma pessoa entusiasmada com a produção do conhecimento, é dedicada e internacionalizada hoje na área da Avaliação Psicológica. Sincera e amiga, mesmo partindo de alguns fundamentos diferentes, ela respeita a diversidade do conhecimento e da Psicologia brasileira. Por essa razão, essa home- nagem é mais do que justa e eu agradeço a sua companhia na construção daquilo que é também o meu sonho - assegurar as crianças de escolas públicas o direito de serem acompanhadas em seu processo de desenvolvimento por uma equipe técnica da qual faz parte um profissional de Psicologia (Raquel de Souza Lobo Guzzo).

Desde adolescente, a Solange se fascinava com a curiosidade e a mente das crianças. Não por acaso, cursou Psicologia e tem, como principal tema de estudo, a criatividade. Até hoje ela guarda esse mesmo fascínio pela mente humana, a paixão pela profissão e a inquietude de um pesquisador. Vinda de uma cidade onde ninguém sabia o que era Psicologia, ela conquistou o Brasil e o mundo, e me enche de orgulho, como filha coruja que sou. Mulher destemida, profissional exemplar, mãe sempre presente e preocupada. É difícil descrevê-la com tão poucos adjetivos, já que ela é uma pessoa tão admirável. Obrigada, mãe, e continue nos encantando com o seu olhar curioso para a Psicologia! (Amanda Muglia Wechsler).

O que dizer da minha mãe... mãe que ao mesmo tempo é guerreira, trabalhadora, carinhosa, profissional de sucesso e SUPER mãe. Uma mineirinha que nasceu na pequena Muriaé e foi conquistar o mundo. Ao finalizar seus estudos no Rio e ir para os EUA fazer seu $\mathrm{PhD}$, ela foi a primeira mulher de sua cidade a conquistar este título. Quando, já de volta ao Brasil e com o nascimento das filhas, ela não deixou a peteca cair, continuou perseguindo seus sonhos. Ao mesmo tempo que cuidava das crianças, viajava para congressos, palestras, dava aulas e ainda achava tempo para se manter em forma. Minha mãe esteve sempre presente. Nunca faltou uma reunião de escola, recital, sempre ajudou na lição de casa. Ao mesmo tempo lá estava ela, correndo de um lado para o outro viajando o mundo, batalhando para ser reconhecida em sua profissão internacionalmente como mulher e latina. Com o passar do tempo, fui entendendo melhor tudo o que ela conseguia fazer e percebi que não tenho uma mãe qualquer... tenho uma SUPER mãe. Hoje o que essa revista homenageia é só reflexo de todos esses anos de trabalho duro, persistência e dedicação. Mãe, tenho tanto orgulho de você por suas conquistas pessoais e profis- 
sionais. Você merece essa homenagem, todas que você já recebeu e virá receber. Parabéns supermãe. Te amo! (Larissa Muglia Wechsler).

Pela relevância do trabalho que Solange Muglia Wechsler vem desenvolvendo na Psicologia, retratada diretamente na sua trajetória profissional aqui retomada, a homenagem a essa importante pesquisadora brasileira mais do que se justifica. A Psicologia brasileira e internacional agradece as importantes contribuições que foram dadas por essa pesquisadora, nos mais diversos níveis de atuação (ensino, pesquisa e formação), bem como deseja que estas se ampliem cada vez mais.

\section{Referências}

Nakano, T.C., Wechsler, S.M., \& Primi, R. (2011). Teste de criatividade figural infantil. São Paulo, SP: Vetor.

Wechsler, S. M. (1996). O desenho da Figura Humana: Avaliação do desenvolvimento cognitivo infantil: Manual para crianças brasileiras. Campinas, SP: Psy.

Wechsler, S. M. (2004b). Pensando criativamente com figuras: Testes de Torrance (versão brasileira). Campinas, SP: LAMP.

Wechsler, S. M. (2004a). Pensando criativamente com palavras: Testes de Torrance (versão brasileira). Campinas, SP: LAMP..

Wechsler, S. M. (2006). Escala de estilos de pensar e criar. Campinas, SP: LAMP.

Witter, G. P. (1996). Entrevista com a fundadora da ABRAPEE Prof. Dra. Solange Muglia Wechsler. Psicologia Escolar e Educacional, 1(1), 83-86. https://doi.org/10.1590/S1413-85571996000100014

\section{Tatiana de Cassia Nakano}

Docente do curso de pós-graduação stricto sensu em Psicologia pela Pontifícia Universidade Católica de Campinas. Campinas - SP. Brasil.

E-mail: tatiananakano@hotmail.com

Endereço para envio de correspondência:

Pontifícia Universidade Católica de Campinas, Centro de Ciências da Vida, Programa de Pós-Graduação em Psicologia. Av. John Boyd Dunlop, s/n., Jd. Ipaussurama, CEP: 13060-904,

Campinas - SP. Brasil.

Recebido 25/07/2018

Aprovado 09/08/2018

Received $07 / 25 / 2018$

Approved 08/09/2018

Recibido 25/07/2018

Aceptado 09/08/2018

Como citar: Nakano, T. C. (2018). Solange Muglia Wechsler: Trajetória profissional. Psicologia: Ciência e Profissão, 38(n.spe), 195-200. https://doi.org/10.1590/1982-3703000209298

How to cite: Nakano, T. C. (2018). Solange Muglia Wechsler: Professional trajectory. Psicologia: Ciência e Profissão, 38(n.spe), 195-200. https://doi.org/10.1590/1982-3703000209298

Cómo citar: Nakano, T. C. (2018). Solange Muglia Wechsler: Trajectoria profesional. Psicologia: Ciência e Profissão, 38(n.spe), 195-200. https://doi.org/10.1590/1982-3703000209298 